\title{
The Scc2/Scc4 cohesin loader determines the distribution of cohesin on budding yeast chromosomes
}

\author{
Igor Kogut, ${ }^{1}$ Jianbin Wang, ${ }^{1}$ Vincent Guacci, ${ }^{2}$ Rohinton K. Mistry, ${ }^{1}$ and Paul C. Megee ${ }^{1,3}$ \\ ${ }^{1}$ Department of Biochemistry and Molecular Genetics, University of Colorado Denver School of Medicine, Aurora, Colorado \\ 80045, USA; ${ }^{2}$ Carnegie Institution of Washington, Baltimore, Maryland 21218, USA
}

\begin{abstract}
Cohesins mediate sister chromatid cohesion and DNA repair and also function in gene regulation. Chromosomal cohesins are distributed nonrandomly, and their deposition requires the heterodimeric Scc2/Scc4 loader. Whether Scc2/Scc4 establishes nonrandom cohesin distributions on chromosomes is poorly characterized, however. To better understand the spatial regulation of cohesin association, we mapped budding yeast Scc2 and Scc4 chromosomal distributions. We find that Scc2/Scc4 resides at previously mapped cohesin-associated regions (CARs) in pericentromeric and arm regions, and that Scc2/Scc4-cohesin colocalization persists after the initial deposition of cohesins in G1/S phase. Pericentromeric Scc2/Scc4 enrichment is kinetochore-dependent, and both Scc2/Scc4 and cohesin associations are coordinately reduced in these regions following chromosome biorientation. Thus, these characteristics of Scc2/Scc4 binding closely recapitulate those of cohesin. Although present in G1, Scc2/Scc4 initially has a poor affinity for CARs, but its affinity increases as cells traverse the cell cycle. Scc2/ Scc4 association with CARs is independent of cohesin, however. Taken together, these observations are inconsistent with a previous suggestion that cohesins are relocated by translocating RNA polymerases from separate loading sites to intergenic regions between convergently transcribed genes. Rather, our findings suggest that budding yeast cohesins are targeted to CARs largely by Scc2/Scc4 loader association at these locations.
\end{abstract}

[Keywords: Scc2; cohesin; sister chromatid cohesion; kinetochore; segregation]

Supplemental material is available at http://www.genesdev.org.

Received May 10, 2009; revised version accepted August 14, 2009.

Accurate chromosome duplication and segregation are essential for the transmission of full chromosomal complements to daughter cells during mitosis. DNA replication produces sister chromatid pairs that are physically linked to one another in a process referred to as sister chromatid cohesion. Cohesion occurs along the entire length of chromosomes and is especially robust in pericentromeric (centromere-flanking) regions, where it plays critical roles in the attachment of sister kinetochores to spindle microtubules emanating from opposite poles of the dividing cell (Eckert et al. 2007), known as chromosome biorientation, and also in resisting precocious sister chromatid separation. Cohesion also promotes efficient DNA double-strand break (DSB) repair by homologous recombination (Ström et al. 2004; Ünal et al. 2004) and participates in the regulation of gene expression (Dorsett et al. 2005; Horsfield et al. 2007; Parelho et al. 2008; Pauli et al. 2008; Schuldiner et al. 2008; Wendt et al. 2008).

${ }^{3}$ Corresponding author.

E-MAIL Paul.Megee@UCDenver.edu; FAX (303) 724-3215.

Article is online at http://www.genesdev.org/cgi/doi/10.1101/gad.1819409.
Cohesion is mediated by a ring-shaped complex called cohesin, whose four subunits are highly conserved in organisms from yeast to humans (for review, see Onn et al. 2008; Peters et al. 2008). Cohesin contains a heterodimer of Smc1 and Smc3 proteins, which are members of the structural maintenance of chromosomes (SMC) family of ATPases that play essential roles in higher-order chromosome organization, and two non-SMC subunits called Mcd1/Scc1 and Scc3. Precisely how cohesin associates with chromatin to mediate cohesion remains an important question. The extended, ring-shaped structure of cohesin has led to the idea that cohesin topologically encircles sister chromatid pairs (Haering et al. 2002; Gruber et al. 2003; Ivanov and Nasmyth 2005). However, other models for cohesin association have not been excluded (Huang et al. 2005; Guacci 2007; Zhang et al. 2008).

Cohesin localization along chromosomes has been mapped at high resolution in several organisms, revealing nonrandom distributions that are critical for cohesin function in chromosome segregation, DNA repair, recombination, and transcriptional regulation. In budding and fission yeast, the highest density of cohesin association is found in broad pericentromeric regions that extend 
several kilobases beyond core centromeric DNA (Blat and Kleckner 1999; Bernard et al. 2001; Nonaka et al. 2002; Glynn et al. 2004; Lengronne et al. 2004; Weber et al. 2004). While cytological studies suggest that pericentromeric cohesin enrichment is a conserved feature of all eukaryotic chromosomes, high-resolution cohesin mapping in higher eukaryotic pericentromeric regions has been thwarted by the presence of repetitive heterochromatin (Fukagawa et al. 2004; Tang et al. 2004; Kitajima et al. 2005; McGuinness et al. 2005; Dai et al. 2006). Interestingly, the characteristics of cohesin-associated regions (CARs) on chromosome arms are distinct from those observed in pericentromeric regions. Cohesin density is less robust at arm CARs and its association is more discrete, spanning only $\sim 0.8-1 \mathrm{~kb}$ rather than kilobases of pericentromeric DNA. Budding yeast arm CARs lack a consensus sequence, but are frequently found in $\mathrm{A}+$ T-rich intergenic regions between convergently transcribed genes (Glynn et al. 2004; Lengronne et al. 2004). In contrast, metazoan cohesins tend to bind within actively transcribed genes (Misulovin et al. 2008; Parelho et al. 2008). Notably, human cohesins frequently colocalize with CTCF, a sequence-specific binding protein involved in chromatin insulator/boundary activity, and cohesin binding at these locations is CTCF-dependent (Parelho et al. 2008; Rubio et al. 2008; Wendt et al. 2008). Thus, while CAR characteristics differ among various organisms, the cohesin distribution within a species is highly reproducible.

While nonrandom cohesin distributions suggest that a spatial regulatory mechanism(s) precisely positions cohesins, the molecular pathways involved in targeting cohesins to particular locations are only beginning to be understood. Cohesin enrichment throughout an $\sim 50-\mathrm{kb}$ domain spanning the 125-base-pair (bp) budding yeast centromere requires a functional centromere/kinetochore complex; centromeric DNA excision or inactivation of kinetochores abolishes this enrichment, and robust cohesin domains assemble de novo flanking an ectopically placed centromere (Megee et al. 1999; Weber et al. 2004; Kiburz et al. 2005; Eckert et al. 2007). Pericentromeric cohesin domain assembly requires the budding yeast homologs of conserved kinetochore proteins that also mediate kinetochore assembly (Eckert et al. 2007). These observations suggest that pericentromeric cohesin enrichment is a conserved function of kinetochores, although the molecular basis of kinetochore-mediated cohesin domain assembly is unknown. A heterochromatin-mediated mechanism for pericentromeric cohesin enrichment has also been described in fission yeast (Bernard et al. 2001; Nonaka et al. 2002). However, this pathway is not required for pericentromeric cohesin enrichment in mammalian cells (Koch et al. 2008), suggesting that kinetochore-directed pathways for cohesin enrichment may also operate in higher eukaryotes. Interestingly, cohesinenriched domains similar to pericentromeric domains assemble flanking DNA DSBs, and this assembly is mediated by histone H2A Ser 129 phosphorylation (Ünal et al. 2004), suggesting that epigenetic features of chromatin also play important roles in cohesin targeting.
Cohesin deposition on chromosomes requires the heterodimeric Scc2/Scc4 loading factor, but its function in deposition is unknown (Michaelis et al. 1997; Ciosk et al. 2000). It has been proposed that the loader facilitates cohesin's SMC-mediated ATPase activity, which may transiently open cohesin rings to allow deposition (Arumugam et al. 2003; Gruber et al. 2006). Alternatively, the loader may participate in local chromatin remodeling, which is a necessary prerequisite for cohesin deposition (Hakimi et al. 2002; Baetz et al. 2004; Huang et al. 2004; Ritchie et al. 2008). Conserved Scc2 homologs, referred to as Mis4, Nipped-B, XScc2, and NIPBL, have been identified in fission yeast, fruit flies, frogs, and humans, respectively (Furuya et al. 1998; Gillespie and Hirano 2004; Rollins et al. 2004; Tonkin et al. 2004), and proteins that are functionally analogous to Scc4 have been identified recently in other species, although their homology with Scc4 is limited (Bernard et al. 2006; Seitan et al. 2006; Watrin et al. 2006).

Despite the high degree of conservation of Scc2 and cohesin subunits, current evidence suggests an evolutionary plasticity with respect to loader-cohesin distributions on chromosomes. Colocalization of these factors is detected throughout the nonrepetitive portions of the Drosophila genome (Misulovin et al. 2008), consistent with the notion that chromosomal cohesin distributions are established by its loader. However, the Drosophila Scc2 homolog Nipped-B was not detected in meiotic chromosome centromeric regions despite cohesin enrichment within these regions (Gause et al. 2008). In contrast, cytological and chromatin immunoprecipitation (ChIP) studies indicate that cohesin and the Scc2/Scc4 loader have nonoverlapping distributions on budding yeast chromosomes (Ciosk et al. 2000; Lengronne et al. 2004), leading to the suggestion that translocating RNA polymerases move cohesins away from initial loading sites and into the intergenic regions of convergently transcribed gene pairs (Lengronne et al. 2004; Bausch et al. 2007). However, cohesins associate with actively transcribed regions of Drosophila chromosomes, challenging the idea that transcription and cohesin association are incompatible per se (Misulovin et al. 2008). It is also important to note that while both cohesin and its loader have been shown to be enriched in budding yeast pericentromeric regions (Lengronne et al. 2004; Ström et al. 2007), the possibility of their colocalization has not been specifically addressed. Thus, while essential for deposition, $\mathrm{Scc} 2 / \mathrm{Scc} 4$ 's contribution to the creation of nonrandom cohesin distributions is unclear.

To better understand how pericentromeric cohesin domains are assembled, we investigated the role of the centromere/kinetochore complex in the pericentromeric enrichment of the Scc2/Scc4 cohesin loader in budding yeast. Our results demonstrate that kinetochores mediate the pericentromeric enrichment of both cohesin and its loader. We also find that Scc2/Scc4 frequently colocalizes with cohesin throughout both pericentromeric and arm regions of chromosomes. Importantly, Scc2/Scc4 binding to CARs is independent of cohesin, strongly suggesting that $\mathrm{Scc} 2 / \mathrm{Scc} 4$ establishes the distribution of 
cohesins on budding yeast chromosomes. These observations indicate that Scc2/Scc4-cohesin colocalization may be more conserved through evolution than previously believed.

\section{Results}

Kinetochore-dependent pericentromeric loader enrichment

The pericentromeric enrichment of Scc2/Scc4 (Lengronne et al. 2004; Ström et al. 2007), together with our demonstration that cohesin enrichment in this region is dependent on the centromere/kinetochore complex (Weber et al. 2004; Eckert et al. 2007), suggested the interesting possibility that high-density cohesin binding within pericentromeric regions is the consequence of the kinetochore-dependent recruitment of the Scc2/Scc4 cohesin loader to these regions. To determine whether kinetochores mediate pericentromeric Scc2/Scc4 enrichment, we examined Scc2 pericentromeric distributions by ChIP under conditions in which kinetochore assembly is defective, and also in a strain that contains an ectopically placed centromere, or neocentromere, on Chromosome III (CHRIII). For these experiments, a version of Scc2 was constructed in which three tandem Flag epitopes, preceded by a 13-amino-acid spacer containing six tandem histidine residues, were fused to the Scc2 $\mathrm{C}$ terminus (Scc2-3Flag). The specificity of immunoprecipitation in ChIPs using this tagged strain relative to an untagged control strain is high (Supplemental Fig. 1). Our strains also contain epitope-tagged Mcd1 (Mcd1-6HA), allowing simultaneous mapping of both Scc2/Scc4 and cohesin distributions along chromosomes. These doubly tagged strains grow indistinguishably from the untagged parental strains, indicating that the tags do not compromise cohesion. Unless otherwise noted, all experiments were performed by synchronizing cultures in the G1 cell cycle period using $\alpha$-factor mating pheromone, and then releasing the cells into fresh media containing the microtubule poison nocodazole to arrest cells prior to anaphase onset. Cultures were then processed for ChIP following formaldehyde cross-linking. ChIP and input DNA samples not subjected to immunoprecipitation were analyzed in PCR reactions that responded linearly to the amount of template DNA added to determine the percentages of total chromatin bound by Scc 2 and Mcd1.

NDC10 encodes an essential budding yeast kinetochore protein that nucleates kinetochore assembly, and this assembly is defective in a conditional ndc10-42 mutant grown at the restrictive temperature $\left(37^{\circ} \mathrm{C}\right)$, causing cells to arrest in mitosis due to the activation of the spindle assembly checkpoint (Doheny et al. 1993). When released from a G1 arrest into fresh media containing nocodazole at the restrictive temperature, the levels of sequences in Mcdl ChIPs corresponding to an $\sim 25-\mathrm{kb}$ centromere-spanning region on CHRIII were reduced approximately threefold on average in the ndc10-42 mutant when compared with $n d c 10-42$ cells maintained at the permissive temperature $\left(23^{\circ} \mathrm{C}\right)$ (Fig. 1A). A similar
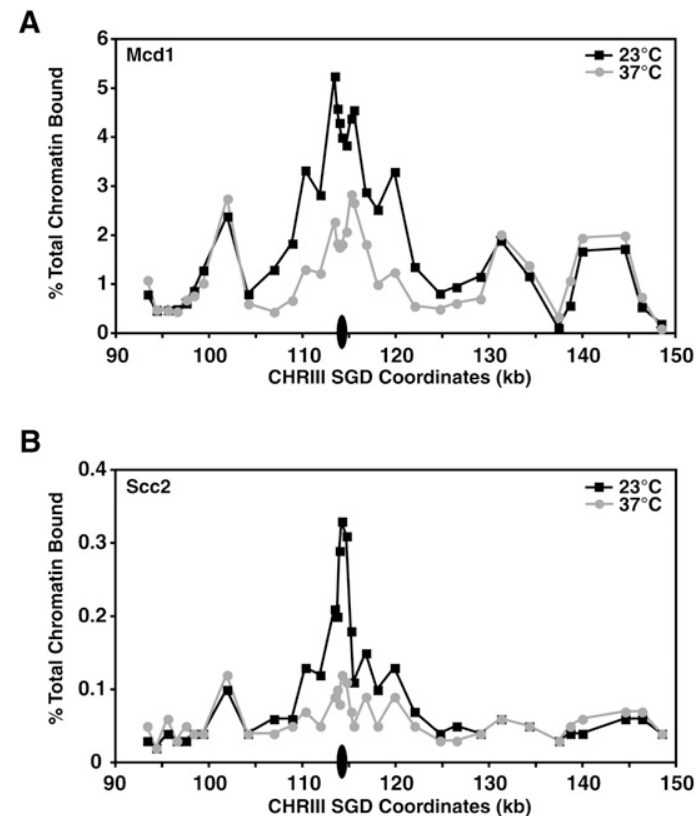

Figure 1. Pericentromeric Mcd1 and Scc2 recruitment is defective in an ndc10-42 mutant. Scc2-3Flag Mcd1-6HA ndc10-42 cells $(1406-43 C)$ were staged in G1 with $\alpha$-factor and then released into fresh medium containing nocodazole. Cultures were split following release from G1, and aliquots were cultured at $23^{\circ} \mathrm{C}$ (black squares) or $37^{\circ} \mathrm{C}$ (gray circles). Following mitotic arrest, cells were fixed and processed for ChIP using anti-HA or anti-Flag serum to detect Mcd1 (cohesin) and Scc2 (loader) distributions, respectively. Quantitation of DNA in the ChIPs, expressed as the percentage of the input DNA, is plotted as a function of the locations of the midpoints of the DNA fragments based on Saccharomyces cerevisiae Genome Database (SGD) coordinates. Centromere positions are indicated by black ovals (not drawn to scale). Association profiles for Mcd1 $(A)$ and Scc2 $(B)$ are shown throughout the CHRIII pericentromeric region.

reduction in Mcdl association was observed previously when isogenic wild-type and ndc10-42 mutant cells were compared at $37^{\circ} \mathrm{C}$ (Weber et al. 2004). Thus, cohesin enrichment in pericentromeric regions is kinetochoredependent (Eckert et al. 2007). Importantly, the levels of CHRIII pericentromeric sequences were similarly reduced within the same pericentromeric interval in the Scc2 ChIPs when ndc10-42 cells were shifted to the restrictive temperature, indicating that pericentromeric Scc2 enrichment is also kinetochore-dependent (Fig. 1B). Interestingly, the levels of DNA corresponding to two CHRXII arm CARs were equivalent in Mcd1 and Scc2 ChIPs performed using ndc10-42 cells grown at $23^{\circ} \mathrm{C}$ or $37^{\circ} \mathrm{C}$ (Supplemental Fig. 2), indicating that the ability of the kinetochore to enhance $\mathrm{Scc} 2 / \mathrm{Scc} 4$ recruitment is limited to pericentromeric regions, as we demonstrated previously for cohesin (Weber et al. 2004; Eckert et al. 2007). Based on these observations, we suggest that the high density of the Scc2/Scc4 loader in pericentromeric regions is directly responsible for cohesin enrichment within these regions. 
As an additional test of the ability of kinetochores to mediate Scc2/Scc4 pericentromeric enrichment, we examined Scc2 association throughout an $\sim 40-\mathrm{kb}$ region spanning a neocentromere inserted on the right arm of CHRIII near Saccharomyces cerevisiae Genome Database (SGD) coordinate $260 \mathrm{~kb}, \sim 145 \mathrm{~kb}$ away from the endogenous centromere location (note that endogenous centromere deletion and neocentromere insertion were performed contemporaneously to prevent the formation of acentric or dicentric chromosomes) (Weber et al. 2004; Kiburz et al. 2005). This neocentromere directed the de novo assembly of an extended, cohesin-enriched domain in flanking regions by amplifying the intrinsic ability of underlying sequences to associate with cohesins. In addition, cohesin association throughout the former pericentromeric region was reduced, reaching levels that are typical of chromosome arms (Weber et al. 2004; Kiburz et al. 2005). In wild-type control cells that have the endogenous centromere, Scc2 is weakly associated within an $\sim 40-\mathrm{kb}$ region centered at SGD $260 \mathrm{~kb}$ (Fig. 2). However, following insertion of centromeric DNA at SGD $\sim 260 \mathrm{~kb}$, we observed fivefold and threefold increases in

A

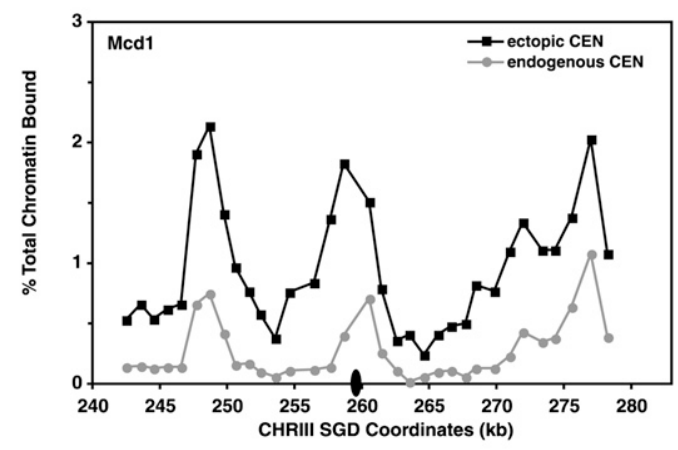

B

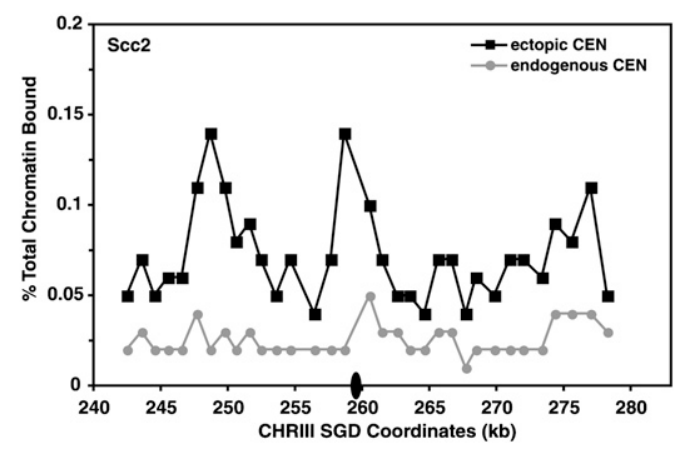

Figure 2. Mcd1 and Scc2 are recruited de novo to neocentromere-flanking regions. Cells containing the CHRIII ectopic centromere (RMY26) and isogenic wild-type cells (PMY656) were staged in G1 with $\alpha$-factor and then released into fresh medium containing nocodazole. Cells were fixed following mitotic arrest and processed for ChIP using anti-HA and anti-Flag antibodies to determine the distributions of Mcd1 and Scc2, respectively. The Mcdl-binding profile $(A)$ and Scc2-binding profile $(B)$ at the ectopic location on endogenous CHRIII (gray circles) and in the presence of the ectopic centromere (black squares) are shown. The location of the ectopic centromere in RMY26 is shown with black ovals (not drawn to scale). the levels of DNA corresponding to neocentromereflanking sequences in the Mcd1 and Scc2 ChIPs, respectively. Increases in Mcd1 and Scc2 association were detected throughout the neocentromeric region, although the regions exhibiting the greatest increases mapped to previously identified CARs. Importantly, we also observed coincident decreases in Mcd1 and Scc2 binding within the former CHRIII pericentromeric region (Supplemental Fig. 3). We conclude from these data that the centromere/kinetochore complex mediates pericentromeric Scc2/Scc4 enrichment, and that this enrichment is independent of a specific DNA consensus sequence in pericentromeric regions.

\section{Loader-cohesin chromosomal distributions}

Our analyses of Mcd1 and Scc2 associations in the ndc1042 mutant cultured at the permissive temperature and also in the CHRIII neocentromere strain revealed that Scc2-binding locations coincided well with previously mapped CARs, suggesting that Scc2/Scc4 colocalizes with cohesin in pericentromeric regions. This finding was unexpected, as earlier studies concluded that these complexes have nonoverlapping distributions on budding yeast chromosomes (Ciosk et al. 2000; Lengronne et al. 2004). To rule out the possibilities that Scc2 is mislocalized in the ndc10-42 mutant even under permissive growth conditions and that Scc2/Scc4-cohesin colocalization is an artifact of the neocentromere-containing chromosome, we next examined Mcd1 and Scc2 distributions by ChIP in mitotically arrested cells that lacked kinetochore subunit mutations or neocentromeres. In agreement with our initial observations, we find that Scc2 distributions in the pericentromeric regions of CHRIII and CHRXIV exhibit similar peaks and valleys of association as those of Mcd1 (Fig. 3). Within both pericentromeric regions, the magnitude of Scc2 association is greatest within $\sim 10 \mathrm{~kb}$ of centromere-spanning DNA, as inferred from the enrichment of these sequences in the Scc2 ChIPs (Fig. 3C,D). Similar observationsnamely, the colocalization with cohesin and a prominent enrichment within an $\sim 10-\mathrm{kb}$ pericentromeric regionwere also obtained on CHRXIV in ChIPs performed using an epitope-tagged version of the second loader subunit, Scc4 (Scc4-3Flag) (Supplemental Fig. 4). Importantly, we also find that loader-cohesin colocalization is not limited to pericentromeric regions. Scc2 and Scc4 are present at a number of previously analyzed arm CARs on CHRIII and CHRXII (Fig. 4; Supplemental Fig. 4), albeit at reduced levels in comparison with pericentromeric regions. Thus, these observations suggest that Scc2/Scc4-cohesin colocalization occurs extensively throughout the budding yeast genome. We note, however, that while the data suggest that Scc2/Scc4-cohesin colocalization is extensive, it is unlikely to be complete. For example, Mcd1 is absent from the Scc2-associated region spanning CHRIII SGD coordinates $\sim 251-255 \mathrm{~kb}$ (Fig. 4C,F). Nevertheless, the magnitude of $\operatorname{Scc} 2 / \mathrm{Scc} 4$ association is greatest in pericentromeric regions and is more modest along chromosome arms, results that closely recapitulate those 
A

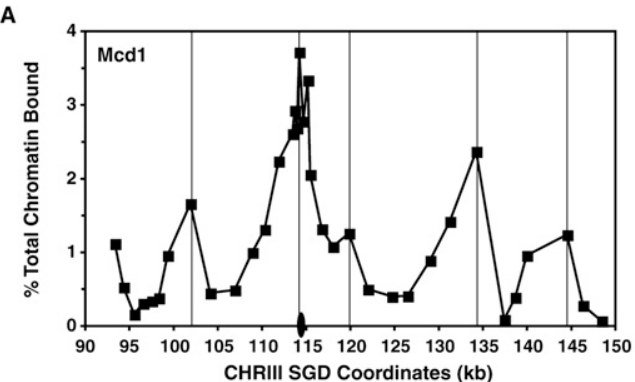

C

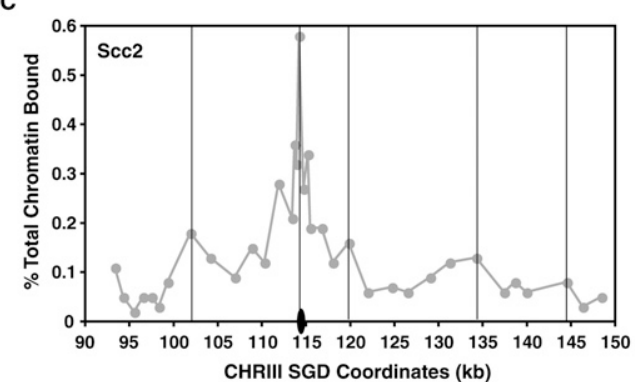

B

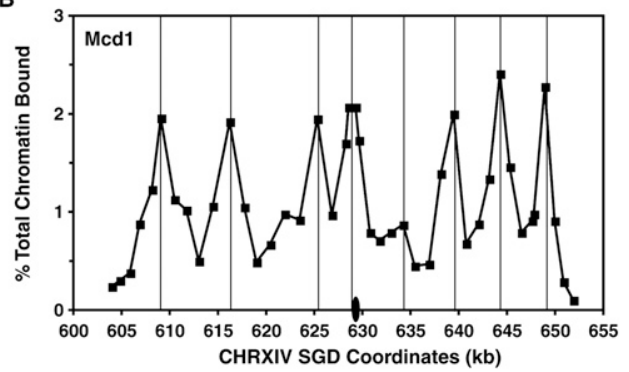

D

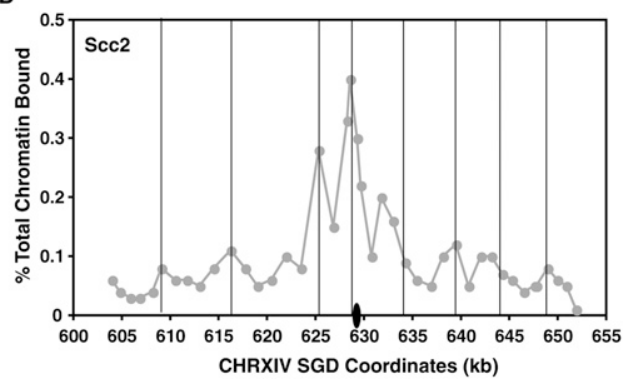

Figure 3. Scc2 colocalizes with pericentromeric CARs. Mcd1-6HA Scc2-3Flag cdc16 cells (PMY615) were staged in G1 and then released into fresh prewarmed $\left(37^{\circ} \mathrm{C}\right)$ media containing nocodazole. Cells were fixed and processed for ChIP using HA and Flag antisera following mitotic arrest. The profiles of $\operatorname{Mcd} 1(A, B)$ and $\operatorname{Scc} 2(C, D)$ association in the pericentromeric regions of CHRIII $(l e f t)$ and CHRXIV (right) are shown. Centromere positions are indicated with black ovals (not drawn to scale). Vertical lines, representing the locations of Mcd1 peaks, are included for comparison of Mcd1 and Scc2 peak binding locations.

obtained for the genomic association of cohesins (Blat and Kleckner 1999; Megee et al. 1999; Laloraya et al. 2000; Glynn et al. 2004; Lengronne et al. 2004; Weber et al. 2004; Eckert et al. 2007).

We also examined Scc2 distributions throughout the $H M R$ silent mating-type locus, which was of interest due to previous observations that an $H M R$-adjacent tRNA gene (tDNA) and its associated RNA polymerase III transcriptional machinery are required to establish cohe- sin association within $H M R$ (Dubey and Gartenberg 2007). These factors, together with cohesin and a Tyl retrotransposon long-terminal repeat, also contribute to the establishment of a boundary on the telomere-proximal side of $H M R$ that limits the spreading of transcriptionally silent chromatin from the $H M R$ locus into flanking euchromatin (Donze et al. 1999). A centromere-proximal silent chromatin boundary at $H M R$ is also present, but its composition is less clear. Interestingly, we detect
A

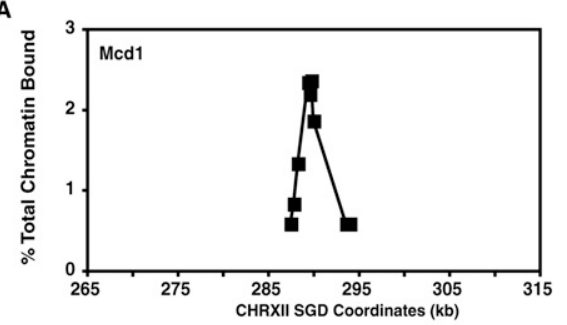

D

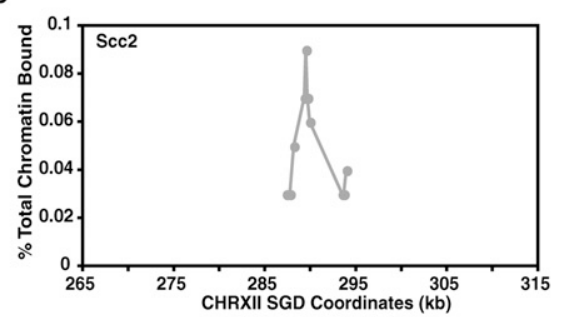

B
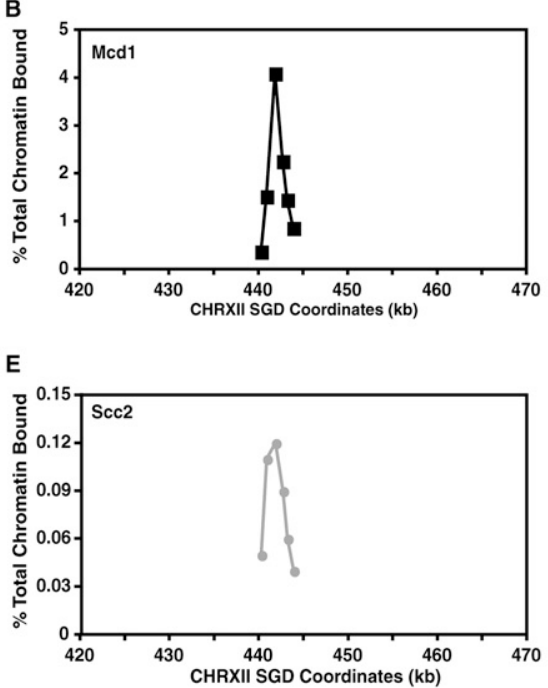

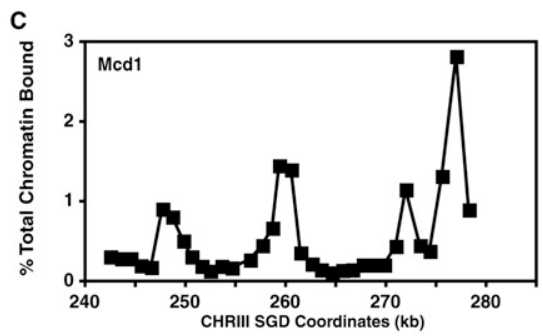

$\mathbf{F}$

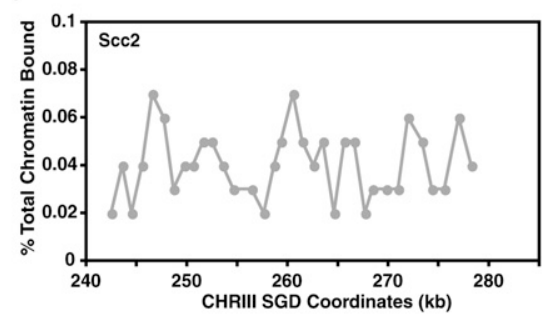

Figure 4. Scc2 colocalizes with arm CAR sites. Mcd1-6HA Scc2-3Flag cells (PMY615) were treated as described in the legend for Figure 3. The profiles of Mcd1 $(A-C)$ and Scc2 $(D-F)$ association at arm CAR locations on CHRXII (left and middle) and on CHRIII (right) are shown. Data are plotted on scales similar to those of pericentromeric regions for comparison. 
Scc2-Mcd1 colocalization at sites that immediately flank $H M R$ (Supplemental Fig. 5). The telomere-proximal CAR, which exhibits higher levels of Mcd1 and Scc2 association, is outside the transcriptionally silenced HMR locus, and cohesin recruitment at this location was shown previously to be independent of the tDNA (Dubey and Gartenberg 2007). In contrast, the centromere-proximal CAR maps within the HMR silent chromatin boundaries. Thus, the presence of the loader at this CAR suggests that cohesin localization within $H M R$ is unlikely to be due solely to the tDNA-directed recruitment of cohesins from distal sites into the locus.

Genomic Scc2 distributions were also mapped recently by ChIP-on-chip microarray analyses of CHRIII through CHRVI following the induction of a single DNA DSB on CHRIII (Ström et al. 2007). However, the potential colocalization of Scc2/Scc4 with cohesin was not addressed in this study. Therefore, we compared the distribution of Scc2-3Flag mapped in control cells lacking induced DNA damage with those of the Mcdl cohesin subunit to determine the extent of Scc2/Scc4-cohesin colocalization throughout the genome in nocodazole-arrested cells (Supplemental Figs. 6-9). Mcd1 and Scc2 ChIP DNA were collected in separate experiments that used microarray formats of different complexities, and so only those positions covered by both arrays were compared. Despite the use of singly tagged Mcd1-6HA or Scc2-3Flag strains rather than one doubly tagged strain, as well as vast differences in array formats, we find good agreement (average correlation coefficient $\sim 0.5$, where 1 and -1 indicate absolute positive and negative correlations, respectively, and where 0 indicates no correlation) between genomic Mcd1- and Scc2-binding locations in the two studies when colocalization was assessed in an unbiased fashion at 100-bp intervals across each chromosome. In striking contrast, pairwise comparisons of Mcd1 or Scc2 distributions with those of Top1 and Top2, DNA topoisomerases whose distributions were collected on the same microarray format used to analyze Scc2 (Bermejo et al. 2007), showed no correlation (correlation coefficients $<0.09$ ), indicating that the colocalization of Mcd1 and Scc2 is highly specific. Moreover, the average correlation coefficient for genomic colocalization increased to $\sim 0.57$ when Scc2 association was assessed at strong cohesin-binding locations, defined as regions where the Mcd1 microarray signal intensity was greater than or equal to $\log _{2}$ 0.75. Lastly, when Mcd1-Scc2 colocalization was assessed throughout $\sim 50-\mathrm{kb}$ pericentromeric regions, where the array signals for both proteins are greatest, the average correlation coefficient increased further to $\sim 0.72$. From these data, we conclude that while colocalization is not absolute, Scc2/Scc4 regularly colocalizes with cohesin at previously identified budding yeast CARs throughout the genome.

\section{Chromosome biorientation displaces Scc2/Scc4 from pericentromeric chromatin}

We demonstrated previously that the magnitude of pericentromeric cohesin association reflects the balance of two opposing activities: constitutive kinetochore-mediated cohesin recruitment, and cohesin displacement due to mechanical tension imposed by the formation of bipolar kinetochore-microtubule attachments, known as chromosome biorientation (Weber et al. 2004; Eckert et al. 2007). To determine whether the magnitude of pericentromeric Scc2/Scc4 association responds similarly to chromosome biorientation, Scc2 and Mcd1 associations were examined in a $c d c 16$ mutant in the presence and absence of kinetochore-microtubule attachments. CDC16 encodes a subunit of the anaphase-promoting complex (APC) and, at the restrictive temperature, $c d c 16$ cells arrest in metaphase due to the absence of APC activity. Nocodazole treatment also inactivates the APC through the spindle checkpoint pathway. Thus, cdc16 cells grown at the restrictive temperature arrest in metaphase with intact bipolar attachments, whereas nocodazole-treated cdc16 cells arrest at the same point, but without kinetochoremicrotubule attachments. We observed that the levels of CHRXIV pericentromeric sequences present in both the Mcd1 and Scc2 ChIPs are reduced throughout an $\sim 30-\mathrm{kb}$ region spanning the kinetochore in cells that retained bipolar kinetochore-microtubule attachments (cdc16 alone) when compared with those observed in cells that lacked microtubules (nocodazole-treated cdc16 cells) (Fig. 5). A similar decrease in Scc4 association was observed in the CHRXIV pericentromeric region of bioriented cdc16 cells compared with the same cells that lacked kinetochore-microtubule attachments (data not shown). In contrast, we observed no changes in the magnitude of Mcd1 or Scc2 association at a CHRXII arm CAR (Supplemental Fig. 10), consistent with previous results showing that the reduction in cohesin association that accompanies chromosome biorientation is limited to pericentromeric regions (Eckert et al. 2007). Thus, mechanical tension imposed by chromosome biorientation coordinately displaces both cohesin and Scc2/Scc4 from pericentromeric regions.

\section{Cell cycle regulation of Scc2/Scc4 association with chromosomes}

We next asked whether Scc2/Scc4 association with CARs varies during the cell cycle. $c d c 16$ cells containing either Scc2-3Flag or Scc4-3Flag were staged in G1 using $\alpha$-factor and then released from the G1 arrest into fresh medium at the restrictive temperature to impose a metaphase arrest. Aliquots of cells were cross-linked with formaldehyde in both $\alpha$-factor and $c d c 16$ arrests and were then processed for Scc2 or Scc4 ChIPs. We found that the levels of Scc2 association in G1 cells within the CHRIII pericentromeric region and also at a CHRXII arm CAR were indistinguishable from those observed in an untagged control strain (Fig. 6A; data not shown). In contrast, the levels of these same sequences in the Scc2 ChIP prepared from cdc16-arrested cells were approximately fivefold higher than those observed in the G1 arrest (Fig. 6A; data not shown). Furthermore, a similar approximately threefold increase in the levels of CHRXIV pericentromeric sequences was also observed in Scc4 ChIPs prepared from 
A

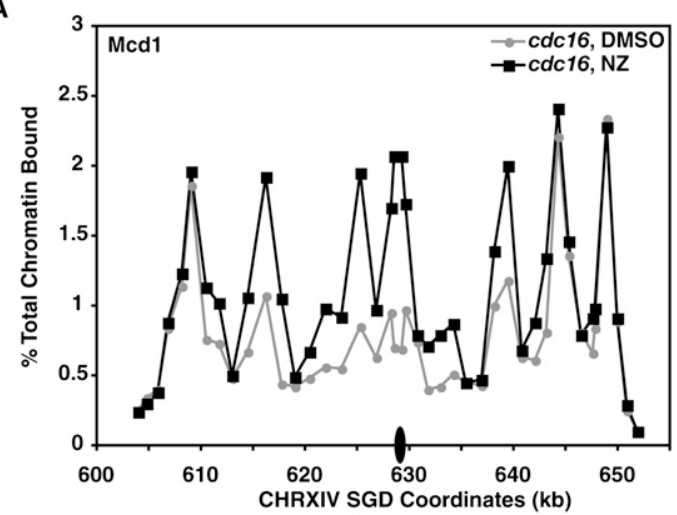

B

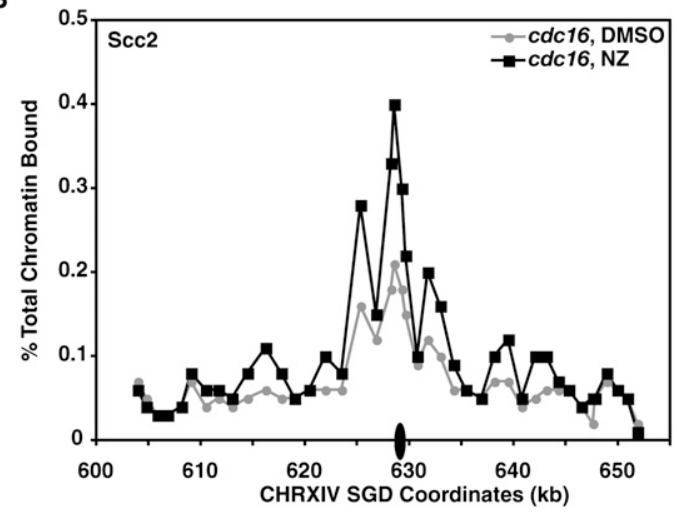

Figure 5. Chromosome biorientation reduces pericentromeric Mcd1 and Scc2 associations. Scc2-3Flag Mcd1-6HA cdc16 cells (PMY615) were staged in G1 with $\alpha$-factor and then released into fresh media at $37^{\circ} \mathrm{C}$ containing either DMSO alone (vehicle control) or nocodazole in DMSO. Upon mitotic arrest $(\sim 3 \mathrm{~h})$, cells were fixed and processed for ChIP using anti-HA and antiFlag sera. The profiles of $\operatorname{Mcd} 1(A)$ and $\operatorname{Scc} 2(B)$ association in the CHRXIV pericentromeric region in the presence (DMSO, gray circles) and absence (nocodazole, black squares) of bipolar kinetochore-microtubule attachments are shown. The positions of centromeres are indicated with black ovals. The data obtained from nocodazole-treated cells are the same data shown in Figure 3 and are replotted here for comparison.

cdc16-arrested cells when compared with G1-staged cells (Supplemental Fig. 11). Thus, the associations of both subunits of the Scc2/Scc4 loading complex increase as cells traverse the cell division cycle.

We considered two possible explanations for these observations. The first possibility is that Scc2 and/or Scc4 protein levels are cell cycle-regulated, and that these proteins are absent or weakly expressed in early cell cycle periods and then accumulate only as cells progress through the cell cycle. However, we find that Scc2 and Scc 4 are present in $\alpha$-factor-arrested cells, and that protein levels vary little through the early stages of the cell cycle (Fig. 6B; Supplemental Fig. 11), when cohesins are first deposited on chromosomes. We conclude that the poor association of Scc2/Scc4 at CARs in G1 is not due to the absence of either Scc2 or Scc4. Another possible explanation for our observations is that $\mathrm{Scc} 2 / \mathrm{Scc} 4$ has a weak affinity for CARs in the absence of functional cohesin complexes. Mcd1 is normally proteolytically cleaved at anaphase onset in the previous cell cycle (Uhlmann et al. 1999), and it is not resynthesized until late G1/early S phase (Fig. 6B; Guacci et al. 1997). To directly test whether the association of Scc2/Scc4 with CARs is dependent on the presence of functional cohesin complexes, we examined mitotic Scc2 CAR association in the conditional cohesin subunit mutants mcd1-1 and smc1-2. Cells were first staged in G1 at the permissive temperature using $\alpha$-factor, and then released into either prewarmed $37^{\circ} \mathrm{C}$ media to inactivate cohesin function or into $23^{\circ} \mathrm{C}$ media as controls. Cultures grown at both temperatures were treated with nocodazole to arrest cells in metaphase, and then fixed and processed for Scc2 ChIP.

A

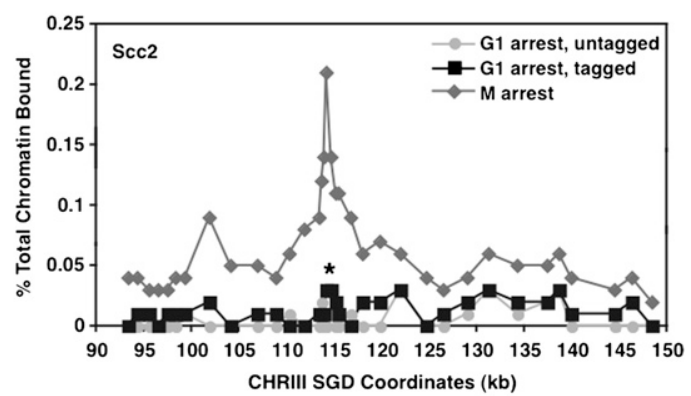

B

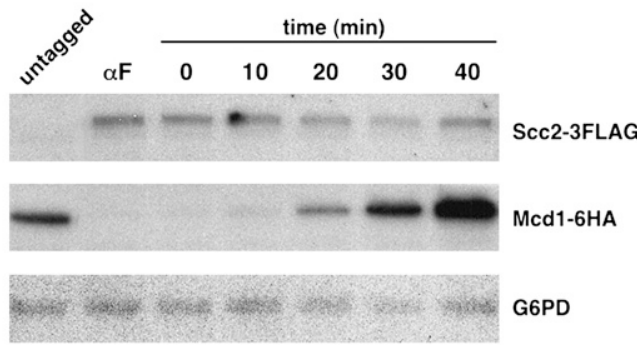

Figure 6. The affinity of Scc2 for chromosomal association is cell cycle-dependent. (A) Scc2-3Flag cdc16 cells (PMY615) and untagged $c d c 16$ control cells $(1847-22 \mathrm{C})$ were staged in G1 with $\alpha$-factor, or released from G1 into fresh media at $37^{\circ} \mathrm{C}$. Aliquots of cells arrested in G1 or M phase were fixed and processed for anti-Flag ChIPs. The levels of sequences corresponding to CHRIII pericentromeric regions present in Scc2 ChIPs are shown in G1-arrested cells in the presence (black squares) or absence (light-gray circles) of the Scc2-3Flag epitope tag, and in Scc2-3Flag-tagged metaphase-arrested cells (darker-gray diamonds). The position of the centromeric DNA (SGD $\sim 115 \mathrm{~kb}$ ) is indicated with an asterisk. $(B)$ Scc2 protein levels were determined by Western blot. Strain PMY615 was synchronized in $\alpha$-factor and then released into fresh media. Aliquots of cells were taken in the $\alpha$-factor arrest at the time of release $(0 \mathrm{~min})$ and at $10-\mathrm{min}$ intervals, as indicated. An asynchronous population of untagged Scc2 Mcd1-6HA cells (1847-22C, first lane) was processed as a specificity control for the Scc2-3Flag blot. The PVDF membrane was divided after transfer of proteins and probed with anti-Flag (Scc2), anti-HA (Mcd1), and anti-glucose-6-phosphate dehydrogenase antibodies, as a loading control. 
We observed that the levels of Scc2 association within the CHRIII pericentromeric regions of mcd1-1 and smc1-2 mutants were similar in the presence or absence of functional cohesin complexes (Fig. 7), as were the levels of Scc2 association with a CHRXII arm CAR (Supplemental Fig. 12). We next determined whether Scc2/Scc4 association with CARs is affected when cohesins are inactivated in metaphase-arrested cells. In this experiment, smc1-2 Scc2-3Flag cells were synchronized in G1, released into fresh media at the permissive temperature in the presence of nocodazole, and then shifted to the restrictive temperature for $1 \mathrm{~h}$ following metaphase arrest. As was the case previously, we detected no reduction in Scc2 association with CARs in the absence of functional cohesin complexes (Supplemental Fig. 13). Taken together, these observations suggest that Scc2/ Scc4 has a low affinity for chromosomes early in the cell cycle and that this affinity increases as cells exit G1 and proceed through the cell cycle. Importantly, the increased affinity of Scc2/Scc4 for chromosomal association is not dependent on the presence of functional cohesin complexes. Thus, the simplest interpretation of these observations is that Scc2/Scc4 binding to CARs precedes that of cohesin, and that cohesin distributions are subsequently established by cohesin deposition at Scc2/Scc4bound locations.
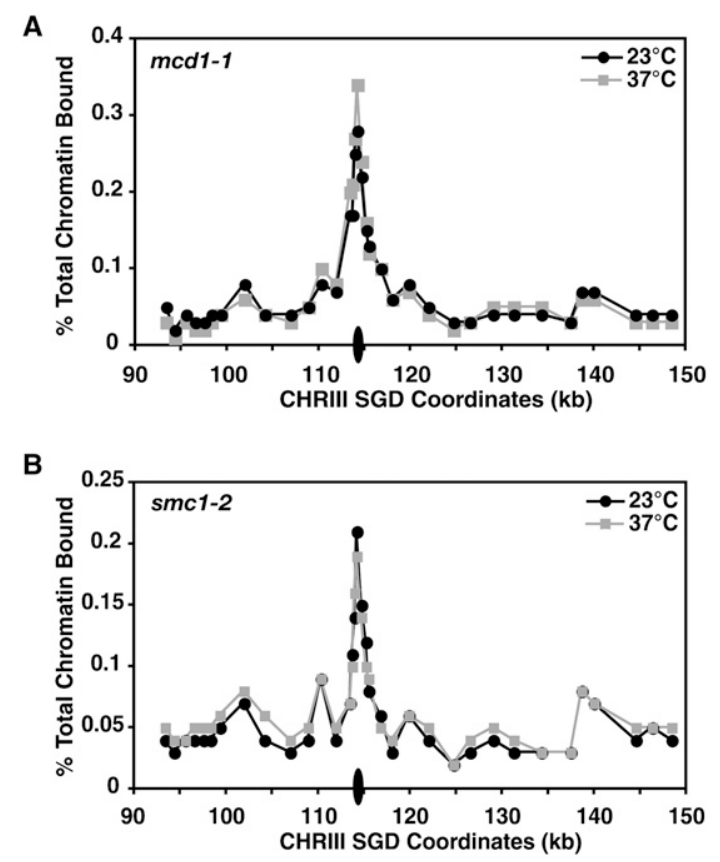

Figure 7. Scc2 localization to CARs is independent of functional cohesin complexes. Scc2-3Flag cells containing mcd1-1 (RMY31) or smc1-2 (1408-35D) were synchronized in $\alpha$-factor and then released into $37^{\circ} \mathrm{C}$ prewarmed media containing nocodazole or into the same media at $23^{\circ} \mathrm{C}$. After reaching metaphase arrest, cells were fixed and processed for Scc2 ChIP. The levels of Scc2 in the CHRIII pericentromeric region are shown in mcd1-1 $(A)$ and smc1-2 $(B)$ mutants grown at $23^{\circ} \mathrm{C}$ (black circles) or $37^{\circ} \mathrm{C}$ (gray squares). The position of the centromere is indicated with a black oval.

\section{Discussion}

The Scc2/Scc4 cohesin loader colocalizes with cohesin

In this study, we provide evidence that cohesin and Scc2/ Scc4 colocalize extensively on budding yeast chromosomes, not only in pericentromeric and arm locations, but also within the specialized chromatin of the $H M R$ locus. Extensive colocalization of these factors was also apparent in comparisons of independently collected Scc2 and Mcd1 genomic mapping data. Furthermore, this colocalization persists beyond the initial deposition of cohesin on chromosomes, which occurs during late G1/early S phase. Taken together, the extensive and persistent colocalization of these factors on budding yeast chromosomes suggests that global cohesin patterns are determined largely by the distribution of its loader, Scc2/Scc4.

Scc2/Scc4-cohesin colocalization on chromosomes is not without precedent. Nipped-B, the Drosophila Scc2 ortholog, has been observed to colocalize with cohesin throughout the nonrepetitive portions of the Drosophila genome by ChIP (Misulovin et al. 2008), although Nipped-B was not detected in cohesin-enriched pericentromeric regions by immunolocalization (Gause et al. 2008). Nevertheless, extensive loader-cohesin colocalization on the chromosomes of simple and complex eukaryotes suggests that this colocalization is likely to be ubiquitous. We note, however, that our observations of Scc2/ Scc4-cohesin colocalization are at odds with previous cytological and ChIP studies in budding yeast, which reported that cohesin and Scc2/Scc4 have nonoverlapping chromosomal distributions (Ciosk et al. 2000; Lengronne et al. 2004). There are several possible explanations for the contrasting findings in these studies. The lack of colocalization of these factors in chromosome spreads may have resulted from prefixation processing of samples, including an enzymatic digestion of yeast cell walls, followed by the mechanical spreading of chromosomes onto microscope slides (Ciosk et al. 2000), leaving ample opportunity for alterations in chromosomal protein interactions. Furthermore, the differences in Scc2/Scc4 distributions we report here from those of Lengronne et al. (2004) may be explained by the use of differently tagged Scc2 proteins in the two studies. C-terminal tagging of Scc2 with six tandem HA epitopes produced modest microarray signals, perhaps due to epitope inaccessibility. Importantly, we note that Scc2 marked with a C-terminal fusion to a peptide containing a biotinylation target site (van Werven and Timmers 2006) was not biotinylated in vivo (YC Chi, C Eckert, and PC Megee, unpubl.), suggesting that Scc2 C-terminal accessibility is limited. In contrast, our use of a 13-amino-acid spacer between Scc2 and three tandem copies of the Flag epitope appears to give higher levels of ChIP, perhaps because the spacer provides a better context for Flag epitope crosslinking and/or immunoprecipitation.

The persistent Scc2/Scc4-cohesin colocalization that we observe is likely to be functionally relevant. Recent studies using photobleaching and live-cell imaging indicate that cohesins are deposited on chromosomes 
from S phase until anaphase onset (Gerlich et al. 2006; McNairn and Gerton 2009). Interestingly, these cohesins have different chromatin-binding stabilities (Gerlich et al. 2006; McNairn and Gerton 2009). A fraction of cohesin becomes stably bound to chromosomes following DNA replication, and this binding persists until sister chromatid separation at anaphase onset, consistent with the notion that this pool mediates the physical association of sister chromatids. In contrast, a second, larger cohesin pool exhibits much shorter residence times on chromosomes, indicative of a rather dynamic association with chromosomes that may be unsuitable for the maintenance of sister chromatid cohesion. The role of the dynamic cohesin pool is unknown, but it may function in the regulation of gene expression or serve as a reservoir of chromosomally associated cohesin that can be converted rapidly into a cohesive (stably bound) form in response to environmental insults that jeopardize genomic integrity, such as DSB formation or the loss of chromosome biorientation. The existence of distinct pools of cohesins that provide functions in chromosome morphogenesis other than sister chromatid cohesion is consistent with an earlier observation that Scc2/Scc4 inactivation in mitotically arrested cells does not result in a loss of viability (Ciosk et al. 2000). Whether Scc2/Scc4-cohesin colocalization is a molecular determinant that distinguishes the stably bound and dynamic cohesin pools remains an interesting question.

The chromosomal association of Scc2/Scc4 at CARs is cell cycle-regulated and is independent of cohesin

Our results also demonstrate that the affinity of Scc2/ Scc 4 for CARs increases during the cell cycle. Despite the apparent absence of CAR-associated Scc2/Scc4 in G1, the chromosomal association of cohesin when the Mcd1 subunit was expressed prematurely in G1-arrested cells suggests that $\mathrm{Scc} 2 / \mathrm{Scc} 4$ is functional at this cell cycle stage (Uhlmann et al. 1999; Ünal et al. 2008), as it is the only known cohesin deposition factor. It is unlikely that Scc2/Scc4 first associates with non-CARs in G1 and is later repositioned to CARs, as this model requires that pericentromeric Scc2/Scc4 (and possibly cohesins) travel $\sim 25 \mathrm{~kb}$ into pericentromeric regions, through regions of convergent transcription, in order to become enriched in centromere-flanking regions. Likewise, while we cannot rule out the trivial explanation that Scc2/Scc4 is bound to CARs in G1 cells but Scc2-3Flag and Scc43Flag epitopes are somehow masked, we favor the hypothesis that the affinity of Scc2/Scc 4 for CARs increases in a cell cycle-regulated manner and that this affinity is subsequently reduced following anaphase onset, which also occurs in Xenopus and human cells (Gillespie and Hirano 2004; Watrin et al. 2006). Interestingly, Scc2/ Scc4's increased affinity for chromosomal association is independent of the deposition of functional cohesin complexes at CARs. Rather, Scc2/Scc4's increased affinity may be mediated by a post-translational modification(s) of Scc2/Scc 4 or by the binding of additional proteins to CARs.
Possible mechanisms for Scc2/Scc4 targeting to pericentromeric and arm regions

How Scc2/Scc4 recognizes and associates with CARs in each cell cycle is currently unclear and will require further elucidation. We demonstrate that Scc $2 / \mathrm{Scc} 4$ is particularly enriched in $\sim 10-\mathrm{kb}$ kinetochore-spanning regions and that this enrichment is kinetochore-dependent. Scc2/ Scc4 enrichment in these regions is likely to play a key role in the maintenance of genomic integrity by ensuring that sufficient levels of cohesin are deposited in pericentromeric regions to constrain sister kinetochores in a manner that promotes chromosome biorientation and stabilizes kinetochore-microtubule attachments (Eckert et al. 2007). While Scc2/Scc4 pericentromeric enrichment may be mediated by an interaction with kinetochore proteins, such interactions are likely to be weak or indirect given that neither cohesin nor Scc2/Scc4 copurifies with kinetochores. Alternatively, Scc2/Scc4 may be targeted to pericentromeric regions by a kinetochore-specific epigenetic mark in the underlying pericentromeric chromatin. Precedent for such a model exists in DNA damage repair, where histone $\mathrm{H} 2 \mathrm{~A}$ phosphorylation is required for the formation of an $\sim 50-$ to $100-\mathrm{kb}$ cohesin-enriched domain flanking a DNA DSB (Ünal et al. 2004). Features of chromatin may also be important for Scc2/Scc4 targeting to intergenic CARs on chromosome arms. While our data are inconsistent with the idea that transcribing RNA polymerases position cohesin rings by driving them away from distinct loading sites, transcription may establish epigenetic marks in the intergenic regions of convergently transcribed genes that favor Scc2/Scc4 association and subsequent cohesin deposition.

While the ability of the kinetochore to effect cohesin enrichment operates bidirectionally over an $\sim 50$-kb pericentromeric region, our findings indicate that kinetochore-mediated Scc2/Scc4 enrichment may be more limited, occurring only within an $\sim 10$-kb pericentromeric region. Do these differences in cohesin and Scc2/ Scc4 distributions provide insight into the mechanism of pericentromeric cohesin enrichment? One possibility consistent with these observations is that the kinetochore-mediated enrichment of Scc2/Scc4 nucleates cohesin deposition immediately adjacent to the kinetochore, which then spreads laterally to form cohesin-enriched domains as additional complexes are deposited. Support for this model was provided by our finding that the insertion of "insulator" elements flanking a kinetochore prevented pericentromeric cohesin enrichment distal to the insulators without affecting the microtubule-binding capability of kinetochores (Eckert et al. 2007). In addition, a pericentromeric cohesin domain established on a chromosome during the preceding $\mathrm{S}$ phase was disassembled following excision of centromeric DNA in mitotically arrested cells, suggesting that the centromere/kinetochore complex provides an essential foundation on which the pericentromeric cohesin domain is assembled (Megee et al. 1999; Weber et al. 2004). How cohesins might spread into distal sequences is currently unknown, but this mechanism does not require a priori that cohesin rings 
encircle sister chromatids. For example, spreading may also be mediated by the oligomerization of extended coiled-coil domains within the SMC subunits of neighboring cohesin complexes.

We demonstrated previously that pericentromeric cohesin association is reduced by the transient separation of sister chromatids in these regions that accompanies chromosome biorientation (Eckert et al. 2007), and we provide evidence here that Scc2/Scc4 binding within these regions responds similarly to chromosome biorientation. These observations suggest that the reduction in pericentromeric cohesin association reflects the combined effects of reduced cohesin deposition in these regions, and also the displacement of cohesin binding due to transient sister chromatid separation. Currently, there is no evidence that Scc2/Scc4 forms a ring-like structure or that it binds topologically to pericentromeric chromatin, as has been proposed for cohesin. Thus, the reduction of pericentromeric Scc2/Scc4 binding following chromosome biorientation may be caused by a reduced affinity for deformed chromatin, produced by poleward microtubule-dependent forces (He et al. 2000). Alternatively, the reduction of pericentromeric Scc2/Scc 4 association on bioriented chromosomes may be a regulated mechanism that prevents further cohesin deposition once kinetochore-microtubule attachments are established. Further experimentation will be required to distinguish between these possibilities.

\section{Scc2/Scc4 and the formation of higher-order cohesion complexes}

Our demonstration that Scc2/Scc4 associates with CARs extends the list of factors that colocalize with cohesin and suggests the intriguing possibility that these factors assemble into a higher-ordered complex on chromosomes. This model is supported by a growing number of physical interactions among cohesion proteins. For example, cohesin interacts physically with Scc2/Scc4 (Arumugam et al. 2003) and also with Pds5 and Rad61/ Wpl1, proteins that promote cohesin's association with chromosomes in budding yeast (Hartman et al. 2000; Panizza et al. 2000; Sumara et al. 2000; Ben-Shahar et al. 2008). Moreover, Pds5 and Rad61 have been shown recently to form a stable tripartite complex with the Scc3 cohesin subunit (Rowland et al. 2009). While the molecular basis for these interactions remains to be elucidated, it is interesting that Scc2, Pds5, and Rad61 share a common structural feature; namely, the presence of several HEAT motif repeats that are thought to mediate protein-protein interactions (Neuwald and Hirano 2000). Dependency relationships indicate a likely order of events in the assembly of such higher-ordered complexes. Based on our data, we propose that the association of Scc2/Scc4 at CARs is a key early event in complex assembly. Interestingly, Scc $2 / S c c 4$ interacts physically and genetically with chromatin remodelers, and remodeling appears to be a prerequisite for cohesin deposition (Hakimi et al. 2002; Baetz et al. 2004; Huang et al. 2004; Ritchie et al. 2008). Whether Scc2/Scc4 association with CARs is a cause or consequence of local chromatin remodeling remains to be determined. In any case, we propose that Scc $2 / \operatorname{Scc} 4$ association with CARs directs cohesin deposition at these locations to establish the well-documented patterns of cohesin association, followed by the recruitment of Pds5 and Rad61, whose localizations to CARs are dependent on cohesin (Hartman et al. 2000; Panizza et al. 2000; Ben-Shahar et al. 2008; Rowland et al. 2009). Whether variants of this higherorder complex exist-for example, those lacking either Scc2/Scc4 or Pds5/Rad61-that are tailored for particular cohesin functions in gene regulation, DNA repair, and sister chromatid cohesion remain important questions, the answers to which will be critical for our understanding of these essential nuclear processes.

\section{Materials and methods}

\section{Strain construction}

Relevant strain genotypes are listed in Supplemental Table 1. SCC2 and SCC4 epitope tagging was performed using standard techniques. PCR products were generated using 86-bp forward oligonucleotides containing sequences corresponding to the last 50 nucleotides (nt) of SCC2 or SCC4, sequences encoding six tandem histidine residues, and $18 \mathrm{bp}$ of homology $\left(5^{\prime}\right.$-AGGGAAC AAAAGCTGGAG-3') with the p3Flag-KanMX plasmid template, which introduces an additional 7 amino acids preceding the three tandem Flag epitopes (Gelbart et al. 2001), and reverse oligonucleotides containing $18 \mathrm{bp}$ of homology (5'-CTATAG GGCGAATTGGGT-3') with p3Flag-KanMX and $50 \mathrm{nt}$ corresponding to sequences immediately after the SCC2 or SCC4 stop codons. Strains of interest, containing epitope-tagged cohesin subunits, were transformed with the PCR product, and transformants were selected on rich medium containing $200 \mu \mathrm{g} / \mathrm{mL}$ G418. The construction of in-frame SCC2-3Flag or SCC4-3Flag tags was confirmed in all strains by DNA sequence analysis.

\section{Yeast cell culture and cell cycle staging for ChIP}

Unless otherwise indicated, cells used for ChIP were first staged in G1 using $\alpha$-factor mating pheromone and then released from arrest by washing twice in media containing Pronase (Sigma), as described previously (Weber et al. 2004). Conditional kinetochore mutants and $c d c 16$ strains were released into $37^{\circ} \mathrm{C}$ prewarmed medium. Cultures used for ChIP were arrested in mitosis using $15 \mu \mathrm{g} / \mathrm{mL}$ nocodazole (Sigma) in $1 \%$ DMSO or in $1 \%$ DMSO alone as a vehicle control. Mitotic arrests, where $\geq 90 \%$ of cells were large-budded, were scored microscopically.

\section{ChIP}

ChIP was performed as described previously (Megee et al. 1999; Weber et al. 2004), with minor modification. Cells were spheroplasted in the presence of protease inhibitors $0.5 \mathrm{mM}$ PMSF, $0.5 \mathrm{mM}$ sodium metabisulfite, $5 \mu \mathrm{g} / \mathrm{mL}$ benzamidine, $0.8 \mu \mathrm{g} / \mathrm{mL}$ pepstatin, $0.8 \mu \mathrm{g} / \mathrm{mL}$ leupeptin), and these inhibitors were included in all subsequent washes of spheroplasts. After washing, spheroplasts were resuspended in FA lysis buffer (Katou et al. 2006) prior to sonication. Sepharose beads, preincubated overnight with antibody, were added to aliquots of chromatin extracts and were incubated for $\sim 18 \mathrm{~h}$ at $4^{\circ} \mathrm{C}$. The sepharose beads were subsequently washed with FA lysis buffer, FA lysis buffer-500 $\mathrm{mM} \mathrm{NaCl}, \mathrm{LiCl}$ detergent wash, and TE, as described (Katou et al. 2006). Immunoprecipitates were eluted from beads 
in elution buffer (Katou et al. 2006) and processed as described previously (Megee et al. 1999; Weber et al. 2004). Immunoprecipitations were performed using monoclonal 12CA5 anti-HA antibody (Roche) and monoclonal M2 anti-Flag antibody (Sigma), as indicated. DNA isolated from ChIPs and diluted total DNA not subjected to immunoprecipitation were subjected to PCR analysis using oligonucleotide primer pairs that amplify 300-bp fragments within the indicated regions. Sequences of PCR primers are available on request. PCR products were resolved on $2.5 \%$ NuSieve (Cambrex) agarose gels containing $0.15 \mu \mathrm{g} / \mathrm{mL}$ ethidium bromide. Digital images of the stained gels were quantitated using Labworks 4.0 software (UVP, Inc.). ChIP experiments were repeated at least twice, and data from one representative experiment are shown.

\section{Bioinformatics analyses}

Scc2 array data were obtained from Gene Expression Omnibus using accession number GSE8270 (Ström et al. 2007). Mcd1 array data were generated using high-density whole-genome tiling arrays manufactured by Roche NimbleGen. DNA purified from Mcdl ChIPs was processed for hybridization using the manufacturer's recommendations. Data sets from Scc2 and Mcd1 arrays, expressed as $\log _{2}$ ratios of immunoprecipitated versus total DNA, were compared only at positions covered by both array formats. Colocalization of Mcd1 and Scc2 was determined by calculating Pearson correlation coefficients (R). In all cases, the $P$-values for statistical significance were $<10^{-7}$. Mcdl array data are available using Gene Expression Omnibus accession number GSE18021.

\section{Protein extraction and Western blotting}

Approximately 10 million cells were boiled for $5 \mathrm{~min}$ in $60 \mathrm{mM}$ Tris-HCl (pH 6.8), $10 \%$ glycerol, $2 \%$ SDS, $5 \%$-mercaptoethanol, and $0.0025 \%$ Bromphenol blue, and then electrophoresed on an $8 \%$ polyacrylamide gel and transferred to a PVDF membrane. After transfer, the membrane was divided into three portions using molecular weight markers, and each piece was blocked for $4 \mathrm{~h}$ at $4^{\circ} \mathrm{C}$ in phosphate-buffered saline containing $0.1 \%$ Tween20 (PBS-T) and $10 \%$ nonfat dry milk. Incubations with primary antibodies were carried out overnight at $4{ }^{\circ} \mathrm{C}$ in PBS-T, $1 \%$ bovine serum albumin, and $1 \%$ nonfat dry milk at the following antibody concentrations: anti-Flag $(1 \mu \mathrm{g} / \mathrm{mL})$, anti-HA $(2 \mu \mathrm{g} / \mathrm{mL})$, and anti-glucose-6-phosphate dehydrogenase (G6PD). Membranes were washed six times, 15 min each wash, in (PBS-T) at room temperature prior to addition of secondary antibodies.

\section{Acknowledgments}

We thank Stephanie Williams, Lena Ström, and Camilla Sjögren for technical advice regarding ChIP of Flag-tagged proteins; Jill Heidinger-Pauli and Doug Koshland for communicating unpublished observations; and Jessica Tyler for plasmids. We thank Sue Biggins, Orna Cohen-Fix, Jill Heidinger-Pauli, Judith Jaehning, Tessie Ng, and Bob Sclafani for critical reading of the manuscript. We also thank Richard Davis for his generous financial support of the computational analyses. This work was supported by National Institutes of Health grant R01-GM66213 to P.C.M.

\section{References}

Arumugam P, Gruber S, Tanaka K, Haering CH, Mechtler K, Nasmyth K. 2003. ATP hydrolysis is required for cohesin's association with chromosomes. Curr Biol 13: 1941-1953.

Baetz KK, Krogan NJ, Emili A, Greenblatt J, Hieter P. 2004. The ctf13-30/CTF13 genomic haploinsufficiency modifier screen identifies the yeast chromatin remodeling complex RSC, which is required for the establishment of sister chromatid cohesion. Mol Cell Biol 24: 1232-1244.

Bausch C, Noone S, Henry JM, Gaudenz K, Sanderson B, Seidel C, Gerton JL. 2007. Transcription alters chromosomal locations of cohesin in Saccharomyces cerevisiae. Mol Cell Biol 27: 8522-8532.

Ben-Shahar TR, Heeger S, Lehane C, East P, Flynn H, Skehel M, Uhlmann F. 2008. Ecol-dependent cohesin acetylation during establishment of sister chromatid cohesion. Science 321: 563-566.

Bermejo R, Doksani Y, Capra T, Katou YM, Tanaka H, Shirahige K, Foiani M. 2007. Top1- and Top2-mediated topological transitions at replication forks ensure fork progression and stability and prevent DNA damage checkpoint activation. Genes \& Dev 21: 1921-1936.

Bernard P, Maure JF, Partridge JF, Genier S, Javerzat JP, Allshire RC. 2001. Requirement of heterochromatin for cohesion at centromeres. Science 294: 2539-2542.

Bernard P, Drogat J, Maure JF, Dheur S, Vaur S, Genier S, Javerzat JP. 2006. A screen for cohesion mutants uncovers Ssl3, the fission yeast counterpart of the cohesin loading factor Scc4. Curr Biol 16: 875-881.

Blat Y, Kleckner N. 1999. Cohesins bind to preferential sites along yeast chromosome III, with differential regulation along arms versus the centric region. Cell 98: 249-259.

Ciosk R, Shirayama M, Shevchenko A, Tanaka T, Toth A, Nasmyth K. 2000. Cohesin's binding to chromosomes depends on a separate complex consisting of Scc2 and Scc4 proteins. Mol Cell 5: 243-254.

Dai J, Sullivan BA, Higgins JM. 2006. Regulation of mitotic chromosome cohesion by Haspin and Aurora B. Dev Cell 11: 741-750.

Doheny KF, Sorger PK, Hyman AA, Tugendreich S, Spencer F, Hieter P. 1993. Identification of essential components of the S. cerevisiae kinetochore. Cell 73: 761-774.

Donze D, Adams CR, Rine J, Kamakaka RT. 1999. The boundaries of the silenced HMR domain in Saccharomyces cerevisiae. Genes \& Dev 13: 698-708.

Dorsett D, Eissenberg JC, Misulovin Z, Martens A, Redding B, McKim K. 2005. Effects of sister chromatid cohesion proteins on cut gene expression during wing development in Drosophila. Development 132: 4743-4753.

Dubey RN, Gartenberg MR. 2007. A tDNA establishes cohesion of a neighboring silent chromatin domain. Genes \& Dev 21: 2150-2160.

Eckert CA, Gravdahl DJ, Megee PC. 2007. The enhancement of pericentromeric cohesin association by conserved kinetochore components promotes high-fidelity chromosome segregation and is sensitive to microtubule-based tension. Genes \& Dev 21: 278-291.

Fukagawa T, Nogami M, Yoshikawa M, Ikeno M, Okazaki T, Takami Y, Nakayama T, Oshimura M. 2004. Dicer is essential for formation of the heterochromatin structure in vertebrate cells. Nat Cell Biol 6: 784-791.

Furuya K, Takahashi K, Yanagida M. 1998. Faithful anaphase is ensured by Mis4, a sister chromatid cohesion molecule required in $\mathrm{S}$ phase and not destroyed in $\mathrm{G}_{1}$ phase. Genes \& Dev 12: 3408-3418.

Gause M, Webber HA, Misulovin Z, Haller G, Rollins RA, Eissenberg JC, Bickel SE, Dorsett D. 2008. Functional links between Drosophila Nipped-B and cohesin in somatic and meiotic cells. Chromosoma 117: 51-66.

Gelbart ME, Rechsteiner T, Richmond TJ, Tsukiyama T. 2001. Interactions of Isw2 chromatin remodeling complex with nucleosomal arrays: Analyses using recombinant yeast histones 
and immobilized templates. Mol Cell Biol 21: 20982106.

Gerlich D, Koch B, Dupeux F, Peters JM, Ellenberg J. 2006. Livecell imaging reveals a stable cohesin-chromatin interaction after but not before DNA replication. Curr Biol 16: 15711578.

Gillespie PJ, Hirano T. 2004. Scc2 couples replication licensing to sister chromatid cohesion in Xenopus egg extracts. Curr Biol 14: 1598-1603.

Glynn EF, Megee PC, Yu HG, Mistrot C, Ünal E, Koshland DE, DeRisi JL, Gerton JL. 2004. Genome-wide mapping of the cohesin complex in the yeast Saccharomyces cerevisiae. PLOS Biol 2: 1325-1339.

Gruber S, Haering CH, Nasmyth K. 2003. Chromosomal cohesin forms a ring. Cell 112: 765-777.

Gruber S, Arumugam P, Katou Y, Kuglitsch D, Helmhart W, Shirahige K, Nasmyth K. 2006. Evidence that loading of cohesin onto chromosomes involves opening of its SMC hinge. Cell 127: 523-537.

Guacci V. 2007. Sister chromatid cohesion: The cohesin cleavage model does not ring true. Genes Cells 12: 693-708.

Guacci V, Koshland D, Strunnikov A. 1997. A direct link between sister chromatid cohesion and chromosome condensation revealed through the analysis of $M C D 1$ in $S$. cerevisiae. Cell 91: 47-57.

Haering CH, Lowe J, Hochwagen A, Nasmyth K. 2002. Molecular architecture of SMC proteins and the yeast cohesin complex. Mol Cell 9: 773-788.

Hakimi MA, Bochar DA, Schmiesing JA, Dong Y, Barak OG, Speicher DW, Yokomori K, Shiekhattar R. 2002. A chromatin remodelling complex that loads cohesin onto human chromosomes. Nature 418: 994-998.

Hartman T, Stead K, Koshland D, Guacci V. 2000. Pds5p is an essential chromosomal protein required for both sister chromatid cohesion and condensation in Saccharomyces cerevisiae. I Cell Biol 151: 613-626.

He X, Asthana S, Sorger PK. 2000. Transient sister chromatid separation and elastic deformation of chromosomes during mitosis in budding yeast. Cell 101: 763-775.

Horsfield JA, Anagnostou SH, Hu JK, Cho KH, Geisler R, Lieschke G, Crosier KE, Crosier PS. 2007. Cohesin-dependent regulation of Runx genes. Development 134: 2639-2649.

Huang J, Hsu JM, Laurent BC. 2004. The RSC nucleosomeremodeling complex is required for cohesin's association with chromosome arms. Mol Cell 13: 739-750.

Huang CE, Milutinovich M, Koshland D. 2005. Rings, bracelet or snaps: Fashionable alternatives for Smc complexes. Philos Trans $R$ Soc Lond B Biol Sci 360: 537-542.

Ivanov D, Nasmyth K. 2005. A topological interaction between cohesin rings and a circular minichromosome. Cell 122: 849-860.

Katou Y, Kaneshiro K, Aburatani H, Shirahige K. 2006. Genomic approach for the understanding of dynamic aspect of chromosome behavior. Methods Enzymol 409: 389-410.

Kiburz BM, Reynolds DB, Megee PC, Marston AL, Lee BH, Lee TI, Levine SS, Young RA, Amon A. 2005. The core centromere and Sgol establish a 50-kb cohesin-protected domain around centromeres during meiosis I. Genes \& Dev 19: 3017-3030.

Kitajima TS, Hauf S, Ohsugi M, Yamamoto T, Watanabe Y. 2005. Human Bub1 defines the persistent cohesion site along the mitotic chromosome by affecting Shugoshin localization. Curr Biol 15: 353-359.

Koch B, Kueng S, Ruckenbauer C, Wendt KS, Peters JM. 2008. The Suv39h-HP1 histone methylation pathway is dispensable for enrichment and protection of cohesin at centromeres in mammalian cells. Chromosoma 117: 199-210.
Laloraya S, Guacci V, Koshland D. 2000. Chromosomal addresses of the cohesin component Mcd1p. J Cell Biol 151: 1047-1056.

Lengronne A, Katou Y, Mori S, Yokobayashi S, Kelly GP, Itoh T, Watanabe Y, Shirahige K, Uhlmann F. 2004. Cohesin relocation from sites of chromosomal loading to places of convergent transcription. Nature 430: 573-578.

McGuinness BE, Hirota T, Kudo NR, Peters JM, Nasmyth K. 2005. Shugoshin prevents dissociation of cohesin from centromeres during mitosis in vertebrate cells. PLoS Biol 3: e86. doi: 10.1371/journal.pbio.0030086.

McNairn AJ, Gerton JL. 2009. Intersection of ChIP and FLIP, genomic methods to study the dynamics of the cohesin proteins. Chromosome Res 17: 155-163.

Megee PC, Mistrot C, Guacci V, Koshland D. 1999. The centromeric sister chromatid cohesion site directs Mcdlp binding to adjacent sequences. Mol Cell 4: 445-450.

Michaelis C, Ciosk R, Nasmyth K. 1997. Cohesins: Chromosomal proteins that prevent premature separation of sister chromatids. Cell 91: 35-45.

Misulovin Z, Schwartz YB, Li XY, Kahn TG, Gause M, MacArthur S, Fay JC, Eisen MB, Pirrotta V, Biggin MD, et al. 2008. Association of cohesin and Nipped-B with transcriptionally active regions of the Drosophila melanogaster genome. Chromosoma 117: 89-102.

Neuwald AF, Hirano T. 2000. HEAT repeats associated with condensins, cohesins, and other complexes involved in chromosome-related functions. Genome Res 10: 1445-1452.

Nonaka N, Kitajima T, Yokobayashi S, Xiao G, Yamamoto M, Grewal SI, Watanabe Y. 2002. Recruitment of cohesin to heterochromatic regions by Swi6/HP1 in fission yeast. Nat Cell Biol 4: 89-93.

Onn I, Heidinger-Pauli JM, Guacci V, Unal E, Koshland DE. 2008. Sister chromatid cohesion: A simple concept with a complex reality. Annu Rev Cell Dev Biol 24: 105-129.

Panizza S, Tanaka T, Hochwagen A, Eisenhaber F, Nasmyth K. 2000. Pds5 cooperates with cohesin in maintaining sister chromatid cohesion. Curr Biol 10: 1557-1564.

Parelho V, Hadjur S, Spivakov M, Leleu M, Sauer S, Gregson HC, Jarmuz A, Canzonetta C, Webster Z, Nesterova T, et al. 2008. Cohesins functionally associate with CTCF on mammalian chromosome arms. Cell 132: 422-433.

Pauli A, Althoff F, Oliveira RA, Heidmann S, Schuldiner O, Lehner CF, Dickson BJ, Nasmyth K. 2008. Cell-type-specific TEV protease cleavage reveals cohesin functions in Drosophila neurons. Dev Cell 14: 239-251.

Peters JM, Tedeschi A, Schmitz J. 2008. The cohesin complex and its roles in chromosome biology. Genes \& Dev 22: 30893114.

Ritchie K, Seah C, Moulin J, Isaac C, Dick F, Berube NG. 2008. Loss of ATRX leads to chromosome cohesion and congression defects. J Cell Biol 180: 315-324.

Rollins RA, Korom M, Aulner N, Martens A, Dorsett D. 2004. Drosophila nipped-B protein supports sister chromatid cohesion and opposes the stromalin/Scc3 cohesion factor to facilitate long-range activation of the cut gene. Mol Cell Biol 24: 3100-3111.

Rowland BD, Roig MB, Nishino T, Kurze A, Uluocak P, Mishra A, Beckouët F, Underwood P, Metson J, Imre R, et al. 2009. Building sister chromatid cohesion: Smc3 acetylation counteracts an antiestablishment activity. Mol Cell 33: 763774.

Rubio ED, Reiss DJ, Welcsh PL, Disteche CM, Filippova GN, Baliga NS, Aebersold R, Ranish JA, Krumm A. 2008. CTCF physically links cohesin to chromatin. Proc Natl Acad Sci 105: 8309-8314. 
Schuldiner O, Berdnik D, Levy JM, Wu JS, Luginbuhl D, Gontang AC, Luo L. 2008. piggyBac-based mosaic screen identifies a postmitotic function for cohesin in regulating developmental axon pruning. Dev Cell 14: 227-238.

Seitan VC, Banks P, Laval S, Majid NA, Dorsett D, Rana A, Smith J, Bateman A, Krpic S, Hostert A, et al. 2006. Metazoan Scc4 homologs link sister chromatid cohesion to cell and axon migration guidance. PLoS Biol 4: e242. doi: 10.1371/journal.pbio.0040242.

Ström L, Lindroos HB, Shirahige K, Sjögren C. 2004. Postreplicative recruitment of cohesin to double-strand breaks is required for DNA repair. Mol Cell 16: 1003-1015.

Ström L, Karlsson C, Lindroos HB, Wedahl S, Katou Y, Shirahige $\mathrm{K}$, Sjögren C. 2007. Postreplicative formation of cohesion is required for repair and induced by a single DNA break. Science 317: 242-245.

Sumara I, Vorlaufer E, Gieffers C, Peters BH, Peters JM. 2000. Characterization of vertebrate cohesin complexes and their regulation in prophase. J Cell Biol 151: 749-762.

Tang Z, Sun Y, Harley SE, Zou H, Yu H. 2004. Human Bub1 protects centromeric sister-chromatid cohesion through Shugoshin during mitosis. Proc Natl Acad Sci 101: 1801218017.

Tonkin ET, Wang TJ, Lisgo S, Bamshad MJ, Strachan T. 2004. NIPBL, encoding a homolog of fungal Scc2-type sister chromatid cohesion proteins and fly Nipped-B, is mutated in Cornelia de Lange syndrome. Nat Genet 36: 636-641.

Uhlmann F, Lottspeich F, Nasmyth K. 1999. Sister-chromatid separation at anaphase onset is promoted by cleavage of the cohesin subunit Scc1. Nature 400: 37-42.

Ünal E, Arbel-Eden A, Sattler U, Shroff R, Lichten M, Haber JE, Koshland D. 2004. DNA damage response pathway uses histone modification to assemble a double-strand breakspecific cohesin domain. Mol Cell 16: 991-1002.

Ünal E, Heidinger-Pauli JM, Kim W, Guacci V, Onn I, Gygi SP, Koshland DE. 2008. A molecular determinant for the establishment of sister chromatid cohesion. Science 321: 566-569.

van Werven FJ, Timmers HT. 2006. The use of biotin tagging in Saccharomyces cerevisiae improves the sensitivity of chromatin immunoprecipitation. Nucleic Acids Res 34: e33. doi: 10.1093/nar/gkl003.

Watrin E, Schleiffer A, Tanaka K, Eisenhaber F, Nasmyth K, Peters JM. 2006. Human Scc4 is required for cohesin binding to chromatin, sister-chromatid cohesion, and mitotic progression. Curr Biol 16: 863-874.

Weber SA, Gerton JL, Polancic JE, DeRisi JL, Koshland D, Megee PC. 2004. The kinetochore is an enhancer of pericentric cohesin binding. PLoS Biol 2: 1340-1353.

Wendt KS, Yoshida K, Itoh T, Bando M, Koch B, Schirghuber E, Tsutsumi S, Nagae G, Ishihara K, Mishiro T, et al. 2008. Cohesin mediates transcriptional insulation by CCCTCbinding factor. Nature 451: 796-801.

Zhang N, Kuznetsov SG, Sharan SK, Li K, Rao PH, Pati D. 2008. A handcuff model for the cohesin complex. J Cell Biol 183: 1019-1031. 


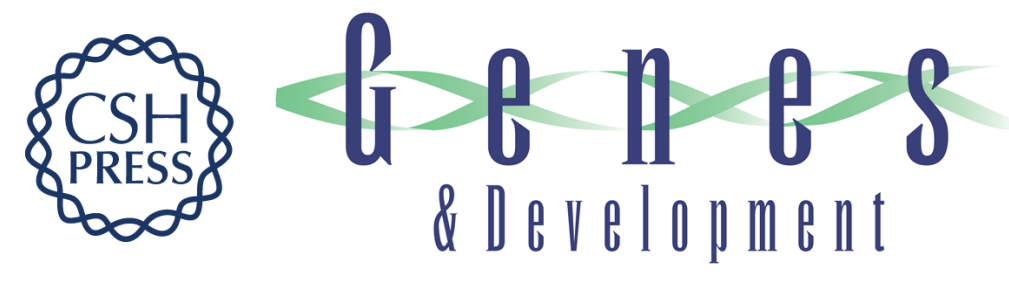

\section{The Scc2/Scc4 cohesin loader determines the distribution of cohesin on budding yeast chromosomes}

Igor Kogut, Jianbin Wang, Vincent Guacci, et al.

Genes Dev. 2009, 23:

Access the most recent version at doi:10.1101/gad.1819409

Supplemental http://genesdev.cshlp.org/content/suppl/2009/10/02/23.19.2345.DC1
Material

References This article cites 71 articles, 25 of which can be accessed free at:

http://genesdev.cshlp.org/content/23/19/2345.full.html\#ref-list-1

License

Email Alerting

Receive free email alerts when new articles cite this article - sign up in the box at the top

Service

right corner of the article or click here.

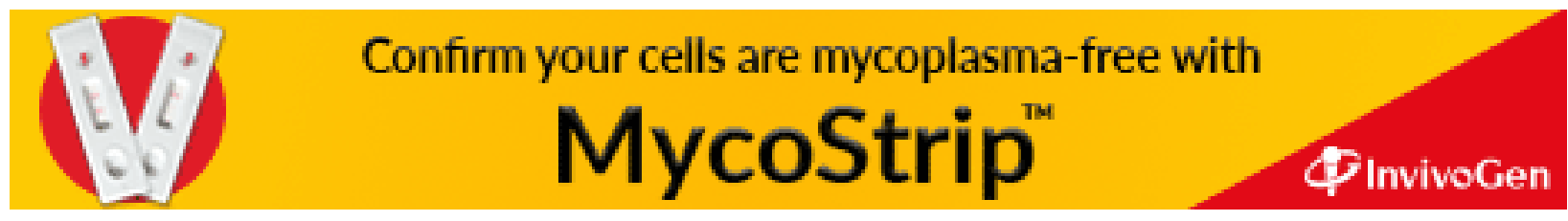

